\title{
DISCLAIMER
}

This document was prepared as an account of work sponsored by an agency of the United States Government. Neither the United States Government nor the University of California nor any of their employees, makes any warranty, express or implied, or assumes any legal liability or responsibility for the accuracy, completeness, or usefulness of any information, apparatus, product, or process

disclosed, or represents that its use would not infringe privately owned rights. Reference herein to any specific commercial product, process, or service by trade name, trademark, manufacturer, or otherwise, does not necessarily constitute or imply its endorsement, recommendation, or favoring by the United States Government or the University of California. The views and opinions of authors expressed herein do not necessarily state or reflect those of the United States Government or the University of California, and shall not be used for advertising or product endorsement purposes. 
UCRL-JC-126095

Preprint

\title{
Radiocarbon Dating Organic Residues at the Microgram Level
}

\author{
Donna L. Kirner, Richard Burky, R. E. Taylor, and John R. Southon
}

This paper was prepared for submittal to

7th International Conference on Accelerator Mass Spectrometry,

Tucson, AZ

May 20-24, 1996

January 16, 1997

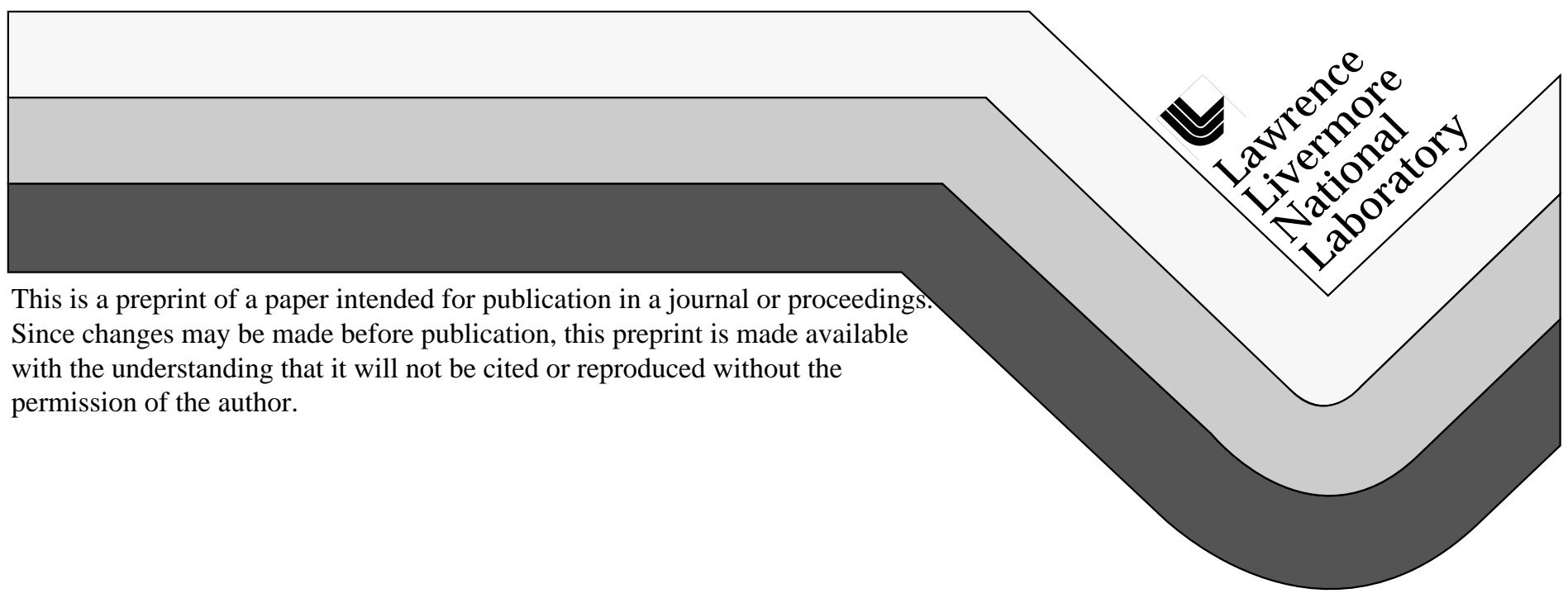


For submission to Nuclear Inutruments and Methods in Phyrics Research for the Proceedings of the Seventh Intarnational Confereace on Accolerator Mass Spectromatry Tucson, Arizona May 20-24, 1996

\section{RADIOCARBON DATING ORGANIC RESIDUES AT THE MICROGRAM LEVEL}

Donna L. KIRNER, Richard BURKY and R. E. TAYLOR

Radilocabon Laboratory, Departinent of Anthopology, Instisure of Coophysics and Planetary Physlcs, University of Callfornia, Riverside, CA 92521 , USA

John R. SOUTHON

Laboratory for Acalerasor Mass Spectromary, Univeraity of Calformia Lawnence Livermors National Laborasory, Liumore, CA 94550 , USA

The relationship between submilligram sample size and ${ }^{14} \mathrm{C}$ activity for sample blanks (wood from Pliocene sediments) and a contemporary standard (oxalic acid (II) for catalytically-reduced graphitic carbon have been examined down to 20 micrograms. The mean age of our 1 milligram wood sample blanks is now about $51.3 \mathrm{ka}(0.168 \mathrm{pMC})$ while tho mean for 20 microgram sample blanks is about $42.9 \mathrm{ka}$. So far, our lowest value for a 1 milligram wood sample blank is about $60.5 \mathrm{ka}(0.056 \mathrm{pMC})$. We have determined a mean ${ }^{14} \mathrm{C}$ age of about $9.4 \mathrm{ka} \mathrm{from} \mathrm{a} \mathrm{suite} \mathrm{of} \mathrm{seven} \mathrm{organic} \mathrm{extracts} \mathrm{from} \mathrm{hair,}$ bone and matting from a mummified human skeleton from Spirit Cave, Nevada. These data indicate that the Spirit Cave human is the third, oldest directly-dated, human skeleton currently known from North America.

\section{Introduction}

Previous studies of sample blanks in AMS systems employing catalytically-reduced graphitic carbon noted the significant increase in backgrounds levels with reductions in submilligram sample weights of graphitized carbon. Vogel et al. [1] proposed that background mass dependence resulted from the introduction of a constant amount of modem carbon during the preparation of the graphitic carbon from $\mathrm{CO}_{2}$. Their suggested model was that, as a constant amount of younger contamination is added, there is a corresponding progressive net increase in $14 \mathrm{C}$ actwity which translates into an increasing younger net apparent ${ }^{14} \mathrm{C}$ age of sample blanks as a function of decreasing sample weight. 
Kimer, Burky, Taylor, Southon

Page 2

At least one other laboratory has reported the same type of mass dependence in sample blanks in addition to increasing variability as a function of sample size [2].

Using anthracite coal, Vogel et al. [1] determined that for samples below about 500 micrograms, the best fit of ${ }^{14} \mathrm{C}$ activity to sample weight indicated that the equivalent of $2.2 \pm 1.1$ micrograms of modem carbon was being added. In their study, the activity of the "modem" ${ }^{14} \mathrm{C}$ contamination was assumed to be equivalent to the defined contemporary activity of a modem ${ }^{14} \mathrm{C}$ standard such as 0.95 oxalic acid []] or 0.74 oxalic acid [II]. The sources of contamination which they evaluated for their combustion step was adsorbed $\mathrm{CO}$ or $\mathrm{CO}_{2}$ on the walls of the Vycor rubing and residual traces of carbon in $\mathrm{CuO}$ used as the oxygen source. They also noted memory effects in the vacuum system and residual traces of carton in the Fe used as the catalyst during the graphitization step. They concluded ty , that $60 \%$ to $70 \%$ of the contamination occurred as a result of the release of adsorbed $\mathrm{CO}_{2}$ from the Vycor tubes used in the combustion step.

\section{UCR/LNL}

We have previously examined the relationship between sample size and ${ }^{14} \mathrm{C}$ activity in milligram and submilligram samples for both sample blanks and modern standards [3,4]. For sample blanks, we utilized wood recovered from Pliocene sediments and for modern standards ANU sucrose and oxalic acid I] (OXI]). In our initial shudy, our results supported the observations of Vogel et al. [1], i.e., that for samples below 500 micrograms, the ${ }^{14} \mathrm{C}$ background values increased as a function of sample weight. However, the best fit of our data characterized the constant addition of the equivalent of $1.03 \pm 0.4$ micrograms of modern carbon, approximately half of that reported by Vogel et al. [1]. The mean $(\mathrm{N}=19)^{14} \mathrm{C}$ age of our 1 milligram sample was about $52.1 \mathrm{ka}$ and our lowest ${ }^{14} \mathrm{C}$ value was $56.1 \mathrm{ka}(0.09 \mathrm{pMC})$. The mean $(\mathrm{N}=2){ }^{14} \mathrm{C}$ value for our smallest samples (10 micrograms) was about $20.3 \mathrm{~kg}$ (9 pMC). For the ANU mples greater than 100 miorograms, our mearured ${ }^{14} \mathrm{C}$ values were within $\pm 1.0 \%$ of the expected activity [5]. However, for ANU samples below $100 \mathrm{mi}-$ 
Kimer, Burky, Taylor, Southon Page 3

crograms, the ${ }^{14} \mathrm{C}$ activity was beiow the expected value by as much as $2 \%$ on a 40 microgram sample.

In an attempt to further reduce potential contamination for submilligram size samples, a new vacuum apparatus was constructed which included the use of a turbo molecular pump with a dry diaphragm backing pump and stainless steel pressure recording transducers. Before initial use, the glass line was washed with isopropyl alcohol and HPLC grade water. We also have employed exclusively trace metal grade reagents in the preparation of samples. Using this apparatus and reagents, we measured ${ }^{14} \mathrm{C}$ activity in wood blanks and $\mathrm{OX}[\mathrm{I}]$ samples in the range from 1000 micrograms to 20 micrograms.

Figure I presents the results for our wood blanks. The mean $(\mathrm{N}-26)^{14} \mathrm{C}$ value for I milligram samples is $51.3 \mathrm{ka}(0.168 \mathrm{pMC})$; the lowest ${ }^{14} \mathrm{C}$ value so far achieved is $60.5 \mathrm{~kg}(0.056 \mathrm{pMC})$. The mean $(N=2)$ apparent ${ }^{14} \mathrm{C}$ age for the 20 microgram wood samples is $42.9 \mathrm{~kg}$. The solid line in Figure 1 shows the relationship between sample weight and ${ }^{14} \mathrm{C}$ activity to fit the rrend of the data points. In this representation, we estimate a constant addition of modern carbon contamination as approximately equivalent to $0.1 \pm 0.05$ micrograms of modem carbon. However, our current data makes it difficult to find a best fit of our current data using the model of an inverse relationship between ${ }^{14} \mathrm{C}$ activity and sample weight below about 100 micrograms unless we also include a constant term of $0.15 \pm 0.05 \mathrm{pMC}$.

Figure 2 represents the relationship of sample weight and ${ }^{14} \mathrm{C}$ activity for $\mathrm{OX}[\mathrm{T}$. Above $300 \mathrm{mi}-$ crograms, all OXI] samples fell within the $\pm 1 \%$ range (dashed line) of $103.98 \mathrm{pMC}$, the expected $O X[n]$ value [6]. Below about 300 micrograms, the results show decreasing ${ }^{14} \mathrm{C}$ activity, though the magnitude of this decrease varies from run to run. There are several possible explanations for these results, including contamination from dead carbon, size-dependent isotopic fractionation in the graphitization step, or fractionation in the ion source itself. We plan future studies to identify the source(s) of these effects. 
Kiner, Burky, Taylor, Southon Page 4

\section{Dating Organic Residues: Sptrtt Cave Emman}

Applying our microgram AMS ${ }^{14} \mathrm{C}$ capabilities, we have undertaken ${ }^{14} \mathrm{C}$ measurements on a suite of hair, bone, and woven plant samples from a human burial recovered from Spirit Cave, Churchill County, Nevada [7, 8]. From the time of its excavation in 1940, it has been regarded as being of late Holocese age-somewhere in the range of 1500 to $2000 \mathrm{BP}$ [9]. Table 1 presents the reaults of the seven ${ }^{14} \mathrm{C}$ values obtained on this burial measured over a period of two years using two different graphite lines. Good agreement between the two sets of measurements suggests that our size dependent backgrounds have been correctly calculated and applied. Three of these values were obtained on total amino acid fractions extracted from plant materials. We are not aware of any previous published ${ }^{14} \mathrm{C}$ values on amino acids extracted from plants.

Based on these data, the Spirit Cave human has been assigned an early Holocene age of about 9.4 lea and is at present the third oldest directly dated human skeleton in North America. Only the Midland [10], Anzick [11], and Mostin [12] human skeletons have older dates assigned to them which are currently considered by most investigators to be valid. Other North American human bone samples previously assigned older ages have been reevaluated and shown to be of middle to late Holocese age [13]. For Anzick and Mostin, the age assignment is based on ${ }^{14} \mathrm{C}$ data; for Midland, uranium series data have been employed.

\section{Conchusion}

The continuing examination of laboratory procectures has reduced levels of contamination in catalytically-reduced graphitic carton samples to the equivalent of $0.1 \pm 0.05$ micrograms of modern carbon. In one case, we have achieved an equivalent age of approximately $60.5 \mathrm{la}$ on a 1 milligram sample of wood recovered from Pliocene sediments. We also have developed techniques to obtain AMS ${ }^{14} \mathrm{C}$ measurements on as little as 20 micrograms of carbon. Using these techniques, we have obtained a suite of ${ }^{14} \mathrm{C}$ values which documents an early Holocene age for the Spirit Cave human.

This work was supported by the Gabrielle 0. Vierra Memorial Fund and University of Califor- 
Kimer, Burky, Taylor, Southon Page 5

nia/Lawrence Livermore National Laboratory with additional support by the Dean of the Callege of Humanities, Arts, and and Social Sciences and the Intramural Research Fund, University of California, Riverside. This is contribution 96/7 of the Institute of Geophysics and Planetary Physics, University of Callfomia, Riverside. The work was performed in part under the auspices of the Department of Energy at the Lawrence Livermore National Laboratory under contract $W-7405-E N G-48$.

\section{References}

[1] J.S. Vogel, D.F. Nelson, and J.R. Southon, Radiocarbon 29 (1987) 323.

[2] D.B. Klinedinst, A.P. McNichol, L.A. Currie, R.J. Schreider, G.A. Klouda, R.F. von Reden, R.M. Verkouteren, and G.A. Jones, Nucl. Instu. and Meth. B92 (1994) 166.

[3] D.L. Kimer, R.E. Tayior and J.R. Southon, Ratiocarbon 37 (1995) 697.

[4] D.L. Kirner, J.R. Southon, P.E. Hare, and R.E. Taylor, in: Archseological Chemistry: Organic, Inorganic, and Biochemical Analysis, ed. A.Y. Orma (American Chemical Society, Washington, DC, 1996), p. 434.

[5] D.J. Donahue, T. W. Linick, A.J.T. Jull, Radiocarbon 32 (1990) 135.

[6] L.A. Currio and H. Polach, Radiocarbon 22 (1980) 933.

[7] R.E. Taylor, P.E. Hare, C.A. Prior, D.L. Kimer, L. Wan, and R. Burky, Radiocarbon 37 (1995) 319.

[8] D.L. Kimer, R. Burky, R.E. Tayior, J.R. Southon, A. Dansie, and D. Twohy, Abstracts, 61st Ann. Meet., Soc. for Amer. Arch., New Orleans, p. 156.

[9] S.M. Wheeler and G.N. Wheeler, Nev. State Mus. Anth. Papers 14 (1969) 70.

[10] C. McKinney, per. comm. (1995).

[11] T.W. Stafford, Jr., in: Method and Theory for Investigating the Peopling of the Americas, ed.

R. Bonnichsen and D. G. Steele (Center for the Study of the First Americans, Oregon State University, Corvallas, 1994), p. 45. 
Kimer, Burky, Taylor, Southon

Page 6

[12] T.S. Kaufnan, Ph.D. diss., Univ, of Calif., Los Angeles (1980).

[13] R.B.Taylor, L.A. Payen, C.A. Prior, P. Slota, Jr., R. Gillespie, J.A.J. Gowlett, R.E.M.

Hedges, A.J.T. Jull, T.H. Zabel, D.J. Danahue and R. Berger, Amer. Antiq. 50 (1985) 136. 
Bimer, Buriky, Taylor, and Southon Table 1

Table 1

Ratiocarbon determinations on organic extracts from human bone and hair: Spirit Cave, Nevada

\begin{tabular}{|c|c|c|c|c|}
\hline $\begin{array}{l}\text { sample } \\
\text { type }\end{array}$ & fraction & sample number & $\begin{array}{l}{ }^{14} \mathrm{C} \text { age } \\
\text { (BP) }\end{array}$ & $\left.{ }_{(\%}^{\delta^{13} \mathrm{C}} \mathrm{PDB}\right)$ \\
\hline \multirow[t]{3}{*}{ hair) } & total organics & UCR-3261-2/CAMS-12354 & $\left.9360 \pm 60^{c}\right)$ & -18.6 \\
\hline & & UCR-3261-2/CAMS-14224 & $\left.9450 \pm 60^{\circ}\right)$ & -18.6 \\
\hline & total amino acids & UCR-3261-4/CAMS-12353 & $\left.9350 \pm 70^{c}\right)$ & -18.0 \\
\hline bonen) & total amino acids & UCR-3260/CAMS-12352 & $9430 \pm 609)$ & -15.7 \\
\hline matb) & total amino acids & UCR-3323/CAMS-24199 & $9430 \pm 70$ & -22.6 \\
\hline \multirow[t]{2}{*}{ tuleb) } & total amino acids & UCR-3324-1/CAMS-24194 & $9410 \pm 60$ & -20.2 \\
\hline & & UCR-3324-2/CAMS-24197 & $9460 \pm 60$ & -21.9 \\
\hline
\end{tabular}

a) Old graphite line.

b) New graphite line.

c) Reference [7]. 
Kimer, Burky, Taylor and Southon

Figure captions

\section{FIGURE CAPTIONS}

Figure 1. Relationship of graphitized sample weight (in micrograms) to ${ }^{14} \mathrm{C}$ activity (in percent modem carbon [PMCD) for Pliocene wood sample: 20 to 1000 micrograms. Above about 100 micrograms, the best fit of the data indicates a constant addition of $0.1 \pm 0.05$ micrograms of modem carbon. Below 100 micrograms, there appears to be a constant term which is equal to $0.15 \pm 0.05$ pMC. Figure 2. Relationship of graphitized sample weight (in mierograms) to ${ }^{14} \mathrm{C}$ activity (pMC) for $\mathrm{OXM}$ contemporary standard: 20 to 1000 micrograms. The dashed line represents $\pm 1 \%$ of $103.98 \mathrm{pMC}$. The typical counting exror for these measurements have been noted for a 100 milligram size sample. 


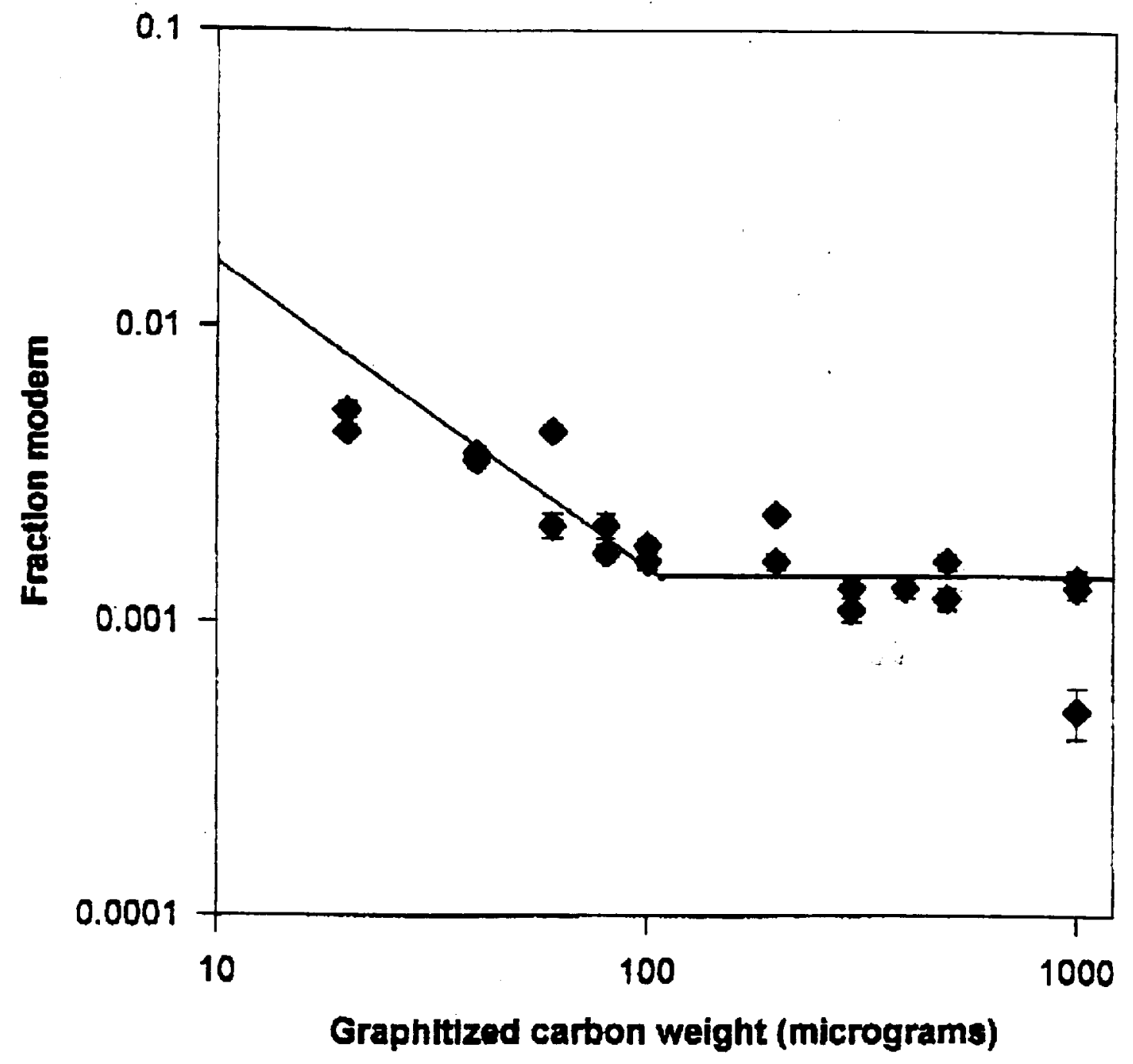

FIGURE 1 


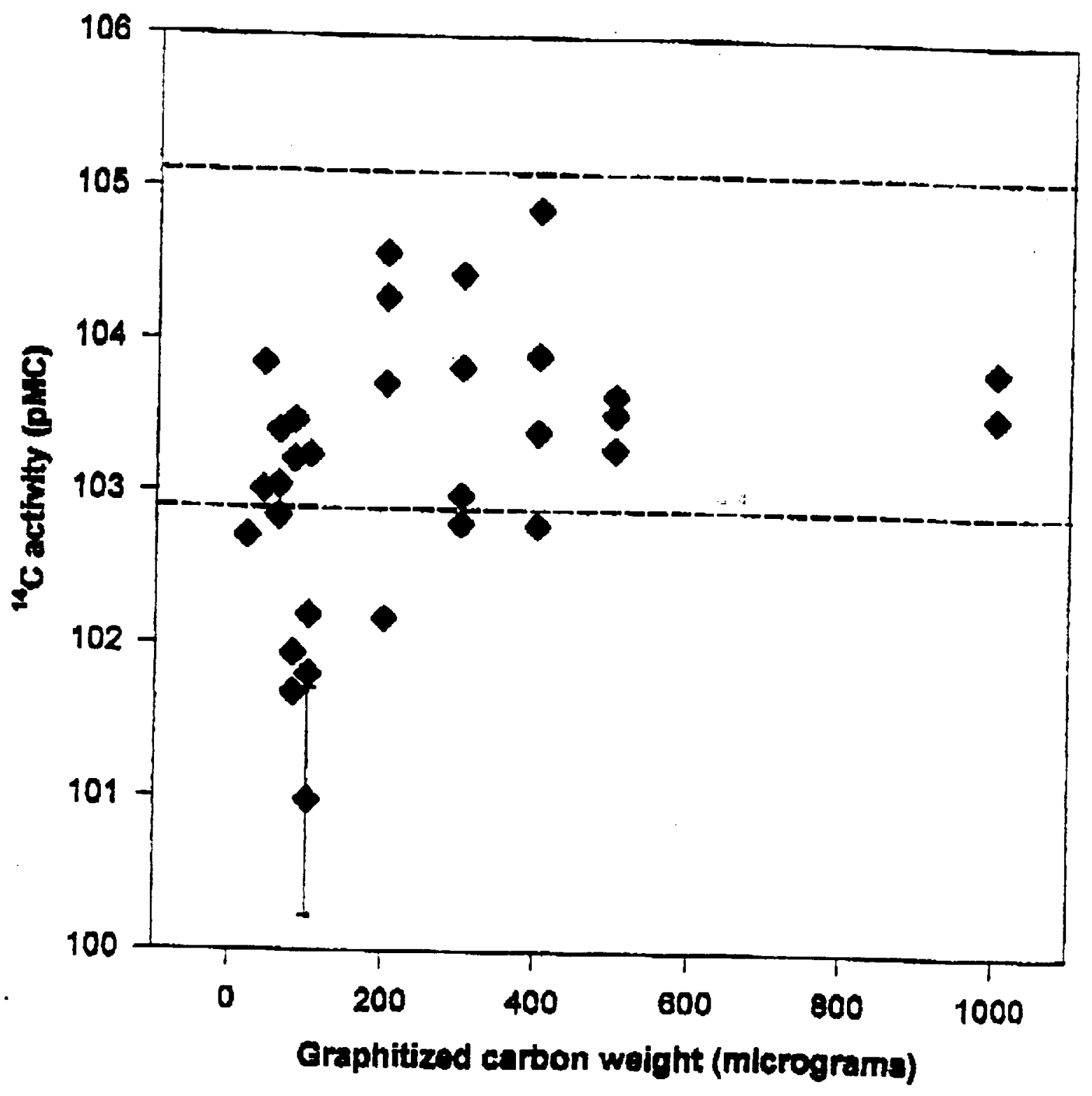

FIGURE 2 


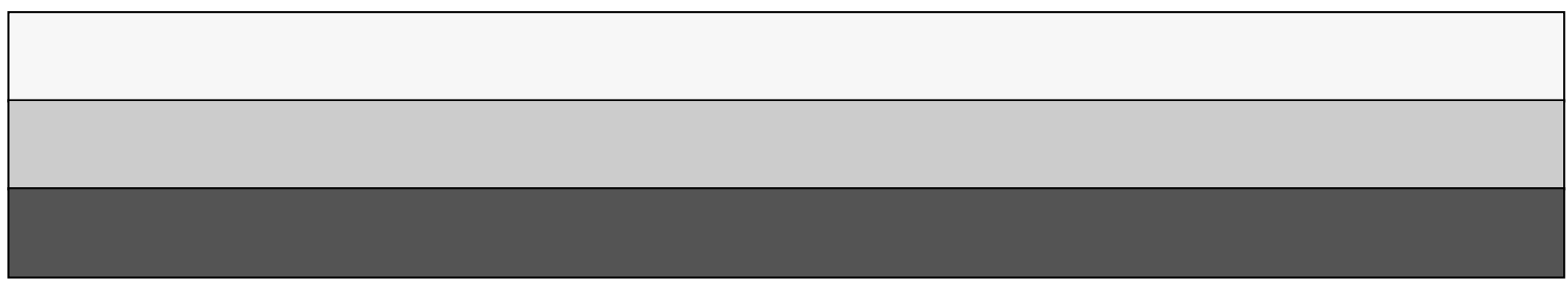

